\title{
Segment Reporting: The Aftermath Effects Of Statement Of Financial Accounting Standards No. 131
}

Brian B. Stanko, (E-mail: bstanko@luc.edu), Loyola University Chicago John Utterback, Financial Analyst, University of Notre Dame Jun Fitzgerald, Research Assistant, Loyola University Chicago

\begin{abstract}
This article addresses the subject of segment reporting and the after effects of SFAS No. 131 "Disclosures about Segments of an Enterprise and Related Information." A comparative analysis of the reporting requirements under SFAS No. 14 and SFAS No. 131 is first presented followed with an examination of corporate disclosures before and after the release of SFAS No. 131. The results are discussed in the context of the Financial Accounting Standards Board's reporting objective "to better understand an enterprises performance."
\end{abstract}

\section{Introduction}

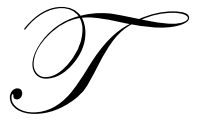

he primary objective of a corporation is to increase shareholders' wealth. To achieve this objective many corporations often engage in several lines of businesses and/or penetrate foreign markets to exploit opportunities to increase profits and cash flows. As a result of this operational diversity, publicly traded corporations are required by the Securities and Exchange Commission (SEC) and the Financial Accounting Standards Board (FASB) to provide information about its reportable operating segments in the footnotes to the financial statements. Prior to 1997, segment reporting was guided by the Statement of Financial Accounting Standards No. 14, "Financial Reporting for Segments of a Business Enterprise" (SFAS No. 14). The Board issued SFAS No. 14 because it believed that users of financial statements would be better able to analyze the underlying drivers of a corporation's historical cash flows and past performance as well as assess future performance projections if the corporation's major segments were disclosed in its financial reports. However, since the issuance of SFAS No. 14 in 1976, the SEC and the security-analyst community criticized the standard for the extent of information that was being disclosed by corporations regarding different segments. The analysts were concerned that they were not receiving enough information about the component parts of corporations.

In response to these criticisms, the FASB issued SFAS No. 131, "Disclosures about Segments of an Enterprise and Related Information," (SFAS No. 131) in June of 1997. The rule established new standards on reportable segments and altered the disclosure requirements related to these segments. As stated in the standard, SFAS No. 131 is intended to help users of financial statements to accomplish the following:

- Better understand the enterprise's performance.

- Better assess its prospects for future net cash flows.

- Make more informed judgments about the enterprise as a whole.

Now, four years later, can financial statement users assert that segment reporting has been improved under SFAS No. 131? Has the release of this pronouncement metamorphosed segment reporting such that companies are providing more useful information and quieting the criticizes of SFAS No. 14 ?

Readers with comments or questions are encouraged to contact the authors via email. 
This study attempts to answer these questions as well as pose additional questions to stimulate further research. The discussion begins with a review of the regulatory environment of financial reporting, the users of financial reports and their informational needs, and the concept of full disclosure. Next, we consider the question of improved reporting under SFAS No. 131. This is accomplished by examining SFAS No. 131, analyzing the differences between the standard and its predecessor standard, and probing the peculiarity of segment reporting in its present form. Finally, we address the needs of the information users and question the aftermath effects of SFAS No. 131 on segment reporting.

\section{The Regulatory Environment, Financial Statement Users, and Full Disclosure}

\subsection{Regulatory Environment}

Official standard setting for accounting principles and procedures basically began after the passage of the Securities Act of 1933 and the Securities Exchange Act of 1934. Congress passed these acts in order to restore public confidence in the stock market after its infamous crash of 1929. The passage of these acts led to the establishment of the SEC in 1934. In relation to its responsibility of administering the Securities Act of 1933 and the Securities and Exchange Act of 1934, the SEC was given the legal authority to prescribe and enforce accounting principles and procedures for any company under its authority (which is any publicly held company). Although the SEC retained its responsibility of enforcing these principles and procedures, it decided to delegate its responsibility for prescribing these principles and procedures to the private professional accounting sector. The FASB, established in 1973, is currently the primary organization responsible for representing the private accounting sector in prescribing accounting principles and procedures. The FASB accomplishes this task primarily through the issuance of Statement of Financial Accounting Standards (of which SFAS No. 14 and SFAS No. 131 are a part of). The FASB also develops accounting concepts and provides guidance on the implementation of standards through its issuance of Interpretations and Bulletins. The SEC still retains the power, however, to establish its own financial reporting requirements or overrule those established the FASB.

\subsection{Financial Statement Users}

The primary users of financial reports are current and potential investors, customers, lenders, suppliers, employees, and regulatory agencies. Each of these different user groups may have different informational needs. Following are the typical information needs and/or uses of financial statement data for these different user groups:

Investors - Investors use financial statements to assess the amounts, timing, and degree of certainty of a corporation's future cash flows. Based on these assessments, they are able to determine whether they should buy, sell, or hold onto current investments in a given corporation.

Customers - Customers use financial statements to determine whether or not they can rely on a company for continuing product support. They can also use financial statements to help them assess a product's future price or a change in a company's product line.

Lenders - Lenders use financial information to assess whether a company will be able to meet the terms of the lending contract. They also may require a borrower to maintain certain financial ratios and other loan covenants in order to protect their interest and help insure that they will receive their expected return on their investment (repayment of loan principal and interest).

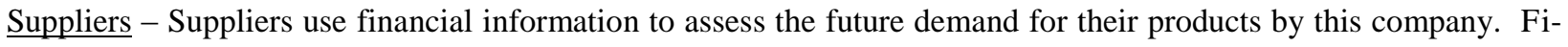
nancial information may also help them determine the extent to which they can advance credit to a company and what the appropriate terms may be.

Employees - Employees, and unions representing these employees, use financial information on their company to help negotiate and determine wage scales, working hours, and other employee benefits. They also use financial information to help determine how well they have performed their duties. Potential employees use financial informa- 
tion on a company to help them determine the culture, stability, and future employment potential of the company and whether these meet their employment needs.

Regulatory Agencies - Regulatory agencies use financial information to monitor whether or not a company has followed regulatory rules. Financial information also assists them in determining a need for the development of future regulations or policies.

The FASB and the accounting profession attempt to meet the information needs of all of these user groups. However, the Board realizes that user groups vary in their financial skills and abilities to interpret financial information. As a result, the Board stipulates that the information provided in the financial statements is intended for those who have a reasonable understanding of business and economic activities and who are willing to learn to properly use the information.

In an attempt to meet the informational requirements of the various user groups, the profession follows some primary principles and objectives when preparing financial reports. These principles and objectives are reflected in the Generally Accepted Accounting Principles (GAAP) made up of, but not limited to, FASB Statements of Financial Accounting Standards, Bulletins, and Interpretations. The goal of GAAP and the primary characteristic of financial reporting is information usefulness. For information to be useful, it must be both relevant and reliablethe secondary characteristics of financial reporting. The Board defines these characteristics as:

- $\quad$ Relevance - Information is useful in helping users making their decisions.

- $\quad$ Predictive Value - Information can help a user's ability to forecast the outcome of past or present events.

- $\quad$ Feedback Value - Information can help a user to confirm or alter their earlier expectations.

- Timeliness - Information is provided in time to help a user make a decision.

- Reliability - Suggests Information that the user can depend on and have confidence in.

- $\quad$ Representation Faithfulness - Information is free from bias and complete in the sense that nothing material is omitted.

- $\quad$ Verifiability - Implies that the information provided could be duplicated by independent measures using the same measurement methods that are stated as being used by those who prepared the financial information.

- Neutrality - Information should be unbiased. In other words, the information should not be prepared in order to attain a particular result or to influence a user's behavior.

Relevant and reliable information contained in the financial reports should also encompass the characteristics of comparability and consistency. Information about an enterprise is more useful if it can be compared across firms (comparability). The same information is more useful if it can be compared with similar information from year to year (consistency).

\subsection{Full Disclosure in Financial Reporting}

Keeping to the characteristics of financial reporting, GAAP requires full disclosure, which means the financial reports reflect sufficient detail to disclose matters of materiality yet sufficient condensation to make the information understandable. Additional amplification can be shown in the notes to the financial statements. Four reasons for disclosure are as follows:

1. To describe and provide additional relevant measures of items recognized on the face of the financial statements.

2. To describe and provide useful measures of items not recognized in the financial statements.

3. To provide information to help investors and creditors assess the risks and potentials of both recognized and unrecognized items.

4. To provide important information during interim periods while accounting issues are being studied in more depth. 


\section{Segment Reporting under SFAS No. 14}

Segment reporting is the disclosure of information about a corporation's major operating components in the notes that accompany the financial statements. As stated earlier, this information helps financial statement users evaluate the corporation by looking at its component parts. This type of information is an effective means of evaluation and is used by companies to manage operations and to make strategic decisions. Segment reporting was first required in 1976 when the FASB issued SFAS No. 14, requiring public corporations to disclose how its segments were performing and how capital was being allocated among them. SFAS No. 14 required corporations to disclose certain financial information by industry segment and by geographic area. An industry segment was defined in SFAS No. 14 as "a component of an enterprise engaged in providing a product or service or a group of related products and services primarily to unaffiliated customers ... for a profit" (SFAS No. 14, ๆ 10.a.). SFAS No. 14 required disclosure of separate revenue, profit, and identifiable assets for each industry segment of a company, and reconciliation of these figures to the consolidated amounts in the financial statements. In addition, disclosure of depreciation, depletion, amortization, capital expenditures, equity-method investments, and the effect of accounting changes on operating profit (loss) for each segment were required. Reportable industry segments comprised of components of the entity meeting the definition of an industry segment whose revenue, profit or loss, and/or assets contributed to at least $10 \%$ of the entity's revenue, profit or loss, and/or assets, respectively.

The issuance of SFAS No. 14, although requiring extensive disclosure on an entity's segments, had little impact on segment reporting. The problem was closely tied to the definition of an industry segment. Many corporations were reporting that it operated in only one segment. A FASB study of 6,935 companies found that $75 \%$ of the respondents operated in only one industry segment. In addition, $43 \%$ of reporting companies with sales greater than $\$ 1$ billion were single-segment companies.

To exemplify how companies interpreted SFAS No. 14, refer to Figure 1 that presents an excerpt of the annual report of Wal-Mart Stores, Inc., for the year ended January 31, 1997.

\begin{tabular}{|l|}
\hline \multicolumn{1}{|c|}{ Figure 1: Wal-Mart Stores, Inc. (01/31/1997) } \\
[as part of Note 1, Summary of Significant Accounting Po7icies] \\
Segment Information \\
The Company and its subsidiaries are principal1y engaged in the operation of \\
mass merchandising stores located in a11 50 states, Argentina, Canada and \\
Puerto Rico, and through joint ventures in Brazi1, China and Mexico.
\end{tabular}

Using the definition of an industry segment as expressed in SFAS No. 14, Wal-Mart Stores, Inc., one of the largest companies in the U.S., was reporting as a single-segment company. Recognizing that companies do not always use products or services to distinguish its organizational components, the FASB replaced industry segment reporting with operating segment reporting as prescribed in SFAS No. 131.

\section{Segment Reporting under the Management Approach}

SFAS No. 131 superseded SFAS No. 14, and established the way public companies disclose segment information and how they choose the information using the "management approach". Under the management approach, companies must identify which segments to report on based on how management - the chief operating decision-maker - organizes the company. Accordingly, a company's organizational structure will evidence which oper- 
ating segments to provide disclosure. SFAS No. 131 defines an operating segment as a component of business:

- That engages in activities from which it may earn revenues and incur expenses (including revenues and expenses relating to transactions with other components of the same business).

- Whose operating results are regularly reviewed by the enterprise's 'chief operating decision maker' to make decisions about resources to be allocated to the segment and assess its performance, and

- For which discrete financial information is available (SFAS No. 131, II 18)

Thus, if a company organizes its segments based on geographic sales regions, separate information regarding those geographic regions will require disclosure. Alternatively, if the company's structure distinguishes its segments based on product lines, segment information about each product segment will require disclosure. SFAS No. 131 allows aggregation of operating segments possessing similar economic characteristics in certain situations.

The management approach not only dictates how to identify operating segments, but also which financial data about these operating segments warrants disclosure. While SFAS No. 14 clearly defined operating profit (loss) and identifiable assets, SFAS No. 131 does not. The information to be disclosed under the current standard is the same information management uses to evaluate performance and make decisions.

Once operating segments have been identified, those segments whose revenue, profit (loss), or identifiable assets constitute at least $10 \%$ of the company's revenue, profit (loss), or identifiable assets, respectively, are considered reportable and require segment disclosure. Also, because SFAS No. 131 requires segment disclosure for $75 \%$ of the company's consolidated revenue, additional segments not meeting the aforementioned criteria should be added until segments comprising $75 \%$ of consolidated revenue are represented in segment disclosure.

Segment reporting under SFAS No. 131 consists of two principal disclosures-Operating Segment Disclosure and Enterprise-Wide Disclosure. Operating Segment Disclosures include general and quantitative information about each reportable operating segment and a reconciliation of the quantitative amounts to consolidated totals. General information discloses how reportable operating segments were identified, if any operating segments were aggregated, and description of products and services of each reportable operating segment. Quantitative disclosures for each reportable operating segment consist of total assets and a measure of profit or loss. Separate information should be provided if management uses them in measuring segment performance. These items include revenues from external customers, revenues from other operating segments, interest income, interest expense, depreciation, depletion and amortization, unusual items, equity-method investment income, income taxes, extraordinary items, and signification non-cash items other than depreciation, depletion, and amortization. In addition, equity-method investments and total expenditures for additions to long-lived assets should be disclosed for each segment if those amounts are included in measuring segment assets. All quantitative disclosures should be reconciled to corresponding enterprise amounts.

Enterprise-Wide Disclosures are composed of information about products and services, information about geographic areas, and information about major customers. Information about products and services discloses revenues generated from external customers for each group of similar products or services. The amount(s) disclosed should be computed based on Generally Accepted Accounting Principles - not based on the management approach. If the information was previously disclosed for operating segments, the information need not be restated.

Information about geographic areas separately discloses revenues generated from external customers from the entity's country of domicile and from all foreign countries in total. If revenues for a particular foreign country or region comprise $10 \%$ or more of the entity's consolidated revenues, that country or region should be disclosed separately. Lastly, information about major customers is required; total revenues generated from any customer that make up $10 \%$ or more of the entity's consolidated income should be disclosed separately. 


\section{Impact of SFAS No. 131 on Financial Disclosure}

The identification of segments based on the management approach has resulted in increased disclosure. Comparison of financial report disclosures for 1996 and 1999 revealed that 59\% of the leading U.S. firms have increased the number of segments for which revenue, profit (loss), and/or asset information was provided. ${ }^{i}$ One of the companies that increased its segment disclosure is Wal-Mart Stores, Inc. Compared to the preceding example (shown in Figure 1), reportable segments has increased from one segment to four operating segments. Wal-Mart now reports discrete information on Wal-Mart Stores, SAM'S Club, International, and Other. Figure 2 presents just a small portion of Wal-Mart's segment disclosure for the year ended January 31, 2000.

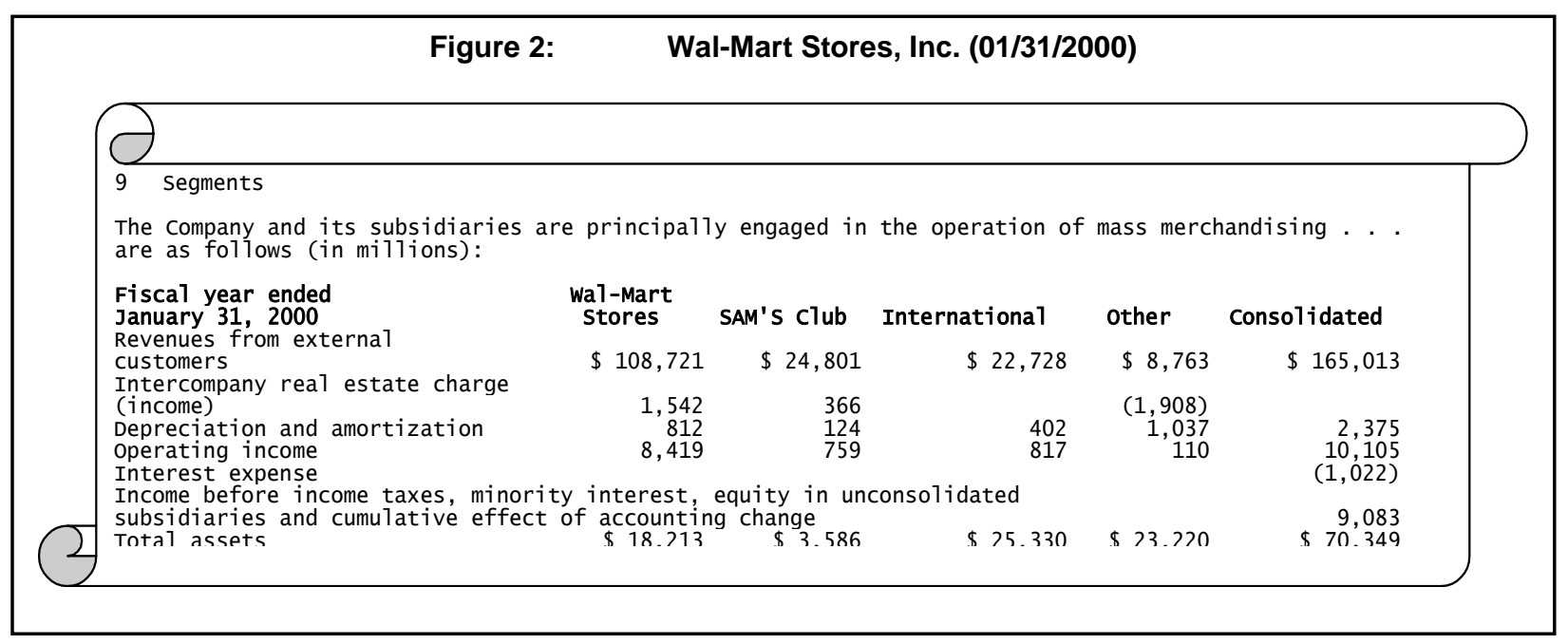

\section{A Closer Look at the Management Approach}

By implementing the management approach to identify company segments and report selected information about those segments, the FASB closed the loophole with respect to identifying segments and provided financial statement users with segment data that is regularly evaluated by management in assessing performance and allocating assets. The FASB believes that the information provided under the management approach illustrates a greater degree of useful information about an entity's segments because users would be in a better position to interpret and analyze prior management decisions and assess the reliability of management's projections for the future. It appears that the management approach provides better information to financial statement users, or does it? Because the management approach does not clearly structure the quantitative information to be disclosed and how to compute this information, segment reporting between companies in similar industries vary.

As stated previously, SFAS No. 131 requires disclosure of only two quantitative data for each reportable segment - segment profit (loss) and identifiable assets. Other quantitative disclosures, such as interest expense, depreciation, and capital expenditures, are only required if the chief operating decision maker uses this information in assessing performance and allocating resources. So, while the number of segments has increased, the new method of segment reporting does not necessarily increase the amount of information provided to financial statement users. To determine the effects of this flexibility of what information warranted disclosure, a comparison of the annual reports of Hewlett-Packard Company and Compaq Computers for the years ending October 31, 1999, and December 31, 1999, respectively, was performed. The comparison revealed that while Hewlett-Packard disclosed segment revenues, operating income, and depreciation/amortization, Compaq only disclosed segment revenues and operating income. This demonstrates that the chief operating decision-maker at Compaq eliminates non-cash expenses when assessing performance, most likely because Compaq does not identify its assets by segment. Accordingly, if Compaq does not use depreciation and amortization in assessing segment performance, are the amounts attributed to depreci- 
ation and amortization included in the amount disclosed as segment operating income? The answer is no. While SFAS No. 14 clearly defined segment operating profit (loss) as segment revenues less all operating expenses, including depreciation and a reasonable allocation of other operating expenses not directly traceable to the segment, SFAS No. 131 does not. Instead, the standard calls for determination of segment profit (loss) based on how management operates the business. Since Compaq does not use depreciation to make decisions about its operating segments, depreciation should not be included in segment profit (loss).

Since the standard defines profit or loss as the way management defines profit or loss to assess the segments' performance, the amount disclosed can include or exclude whatever management considers or not, provided the reporting entity discloses how it measured the amount. This application of the management approach certainly allows financial statement users to see the company's operations through management's eyes, but it may provide a little too much flexibility. It is this lack of guidance why FASB-member Mr. James J. Leisenring dissented from adopting SFAS No. 131, stating that it "allows any measure of performance to be displayed as segment profit or loss as long as that measure is reviewed by the chief operating decision maker".

Not only does the management approach lack guidance on the quantitative amounts disclosed for a company's segments, but it also yields incomparable segment data between similar entities. Note that SFAS No. 131 requires identification of operating segments based on the way management organized the entity. Therefore, segment data of companies that appear to be in similar businesses can appear very dissimilar.

To exemplify the lack of comparability, consider Dell Computers and Gateway, Inc. Both are publicly traded U.S. corporations and vendors of personal computers and related products/services. Additionally, both firms segregated component units by geographic regions in their respective 1999 annual reports. However, Gateway further separates its U.S. performance by customer class (Consumer and Business). Dell's annual report does not even disclose U.S. performance but rather a performance measure of the "Americas." While Dell's U.S. revenues are disclosed as required under the Enterprise-Wide Disclosures of SFAS No. 131, profit or loss for U.S. operations is not provided. Thus, financial statement users for these two firms are denied the ability to compare segment data between the firms because the segment units are not alike.

\section{Conclusion}

Comparability is certainly not what the FASB was trying to accomplish when releasing SFAS No. 131. They wanted to provide financial statement users the ability to see why management made certain decisions, predict what management may do in the future, and recognize which areas of the company are getting the firm's resources. The FASB also wanted financial statement users to be equipped with some of the information available to management so that the users would be able to better understand forecasts, strategies, and other information that may be made available to them. In short, the FASB wanted to make segment reporting more relevant and reliable ... more useful.

It is hard to conclude at this point whether segment reporting is more useful under the new standard. While companies have increased segment data disclosures in their financial statement, it is quite possible that that is simply because the release of SFAS No. 131 heightened alertness and acquiescence to the topic. Is more always better?

In a 1999 AIMR Corporate Disclosure Survey, 69\% of the respondents believed that the overall quality of financial information disclosed by publicly traded companies has improved - but only 5\% attributed it to segment information. In addition, $86 \%$ of analysts/portfolio managers who participated in the survey regarded segment reporting as important, yet only $36 \%$ believed that the information was of high quality. The survey also included comments from respondents about why they feel financial reporting has improved or deteriorated. Despite the fact that most of the comments about segment reporting were positive and simply as a result of greater detail, one respondent proclaimed that segment information is "often presented in a deceiving manner."

Whether or not segment reporting has improved, or has become more useful, is anyone's call. But to reach a consensus on opinion, one must consider the purpose of segment reporting. To recap, when SFAS No. 14 was is- 
sued in 1976, it was intended to provide more relevant information to users by requiring companies to disclose important distinct segments of their enterprise. The FASB theorized that by a company providing segment information, users of their information would be able to better assess the underlying causes of prior cash flows and performance and also be able to better assess future prospects for the company. However, companies were abusing the definition of industry segment as defined in SFAS No. 14, reporting only one segment. In response to the growing number of complaints about the lack of useful segment information, the FASB issued SFAS No. 131 in 1997. This was an attempt to close the loophole on what was being considered a segment and to provide users with information similar to that which the company management uses to make its decisions. Has SFAS No. 131 accomplished this? Companies are reporting a greater number of segments and financial statement users are now able to see through management's eyes via disclosures prepared under the management approach.

SFAS No. 131 may not be $100 \%$ successful in providing all users with more useful information. When asking input from users of financial statements about whether segment data would be more useful if it was presented through management's perspective or if it was comparable with information from other, similar companies, Dr. David Diltz, Professor of Finance at the University of Texas at Arlington replied,

I can envision research projects about management behavior (or compensation) and segment finances that could be done with segment data reported as managers define segments. On the other hand, cross-sectional studies of corporate control activities like spin-offs, $L$. B. O.'s, diversification, etc. would benefit from consistent segment definitions. So, the bottom line is, I'd like to have both.

Unfortunately, the cost of providing both forms of information well exceeds the benefits. When the FASB resolved to use the management approach, it did so with consideration that this is information is already being prepared the management. The cost and additional effort of disclosing this information in the financial statements should not be as significant as if corporations were forced to produce this information for the sole purpose of segment reporting.

Overall, if most companies follow the spirit of the SFAS No. 131 not just its literal definition, most financial statement users should receive more useful information on company segments. Not only has it resulted in a greater number of segments being disclosed, it provides financial statement users with information similar to the information that management uses in making decisions. With this additional information, users should be in a better position to assess a company's past performance and assess its future potential.

\section{Suggestions for Future Research}

Future research can be pursued in a number of ways. First, a framework similar to this one can be applied to a greater population. For example, a study of corporate disclosure before and after the release of SFAS No. 131 could be developed to include the top 100 or 500 U.S. corporations. Second, research could be conducted to determine whether or not segment information is of value to investments analysts and other users of financial information. The results can be used to determine the amount and type of information disclosed in a shareholder annual report or annual report 10-K.

\section{References}

1. Albrecht, David W., and Niranjan Chipalkatti. "New Segment Reporting." The CPA Journal. May 1998: $46-51$.

2. Bunce, Kenneth R. "It's Time to Implement Segment Disclosures." Journal of Accountancy. January 1999: 43 - 45.

3. Chasteen, Lanny G., Richard E. Flaherty, and Melvin C. O'Connor. Intermediate Accounting. $6^{\text {th }}$ ed. Boston: McGraw-Hill, 1998.

4. Cunningham, Lawrence A. “The Endless Quest for Integrity in Financial Reporting.” Benjamin N. Cardozo School of Law Website. 3 March 2001. <http://www.cardozo.yu.edu/heyman/integrity.html>.

5. $\quad$ Diltz, David. "Re: Segment Reporting Questionaire.” Electronic-mail to Jun Fitzgerald. 17 April 2001.

6. "Disclosures About Segments of an Enterprise." Deloitte \& Touche Publications Website. 3 March 2001. 
<http://www.dttus.com/PUB/segments/default.htm>.

7. Financial Accounting Standards Board. "Summary of Statement No. 131 Disclosures about Segments of an Enterprise and Related Information." Summaries/Status Page, FASB. 3 March 2001. <http://accounting.rutgers.edu/raw/fasb/st/summary/stsum131.htm/>.

8. Financial Accounting Standards Board. FAS 14: Financial Reporting for Segments of a Business Enterprise. December 1976.

9. Financial Accounting Standards Board. FAS 131: Disclosures about Segments of an Enterprise and Related Information. June 1997.

10. Fleishman-Hillard Research, Inc. for AIMR. AIMR Corporate Disclosure Survey. February 2000. Association for Investment Management and Research Website. 2 March 2001. <http://www.aimr.com/pdf/corpdiscsurv.pdf $>$.

11. Napolitano, Gabrielle U., and Patricia D. McQueen. Letter to Jonathan G. Katz. 27 July 1998. Association for Investment Management and Research Website. 21 April 2001. <http://www.aimr.org/advocacy/98commltr/segreport.html>.

12. Nichols, Linda, and Rebecca Gallun. "Coping With the New Segment Standard." The CPA Journal. April 1998: 54 - 55.

13. Nichols, Nancy B., and Donna L. Street. "Segment Information: What Early Adopters Reported.” Journal of Accountancy. January 1999: 37 - 41.

14. Sanders, Joe, Sherman Alexander, and Stan Clark. "New Segment Reporting: Is It Working?" Strategic Finance Magazine. December 1999: 35 - 38.

15. Securities and Exchange Commission. Segment Reporting Final Action. 17 CFR Parts 210, 229, 240 and 249. 8 March 2001. <http://www. sec.gov/rules/final/33-7620.txt/>.

16. "SFAS 131 (1997) IAS 14 (Revised, 1997) Segment Reporting." 3 March 2001. <http:// www.acsondhi.com/discussion/SRprtP1.htm/>.

\footnotetext{
Companies used in research consisted of the top 25 rated firms based on Fortune 500 ranking for the year 2000 - based on fiscal year ended on or before January 31, 2000. Firms discarded from the population are Citigroup, State Farm Insurance Companies, and TIAA-CREF. Citigroup was discarded because several business combinations have occurred since 1996, altering the organizational structure inordinately that the comparative value is null. State Farm and TIAA-CREF were discarded because they were not a publicly traded company.
} 
Notes 